Ciência Florestal, Santa Maria, v. 23, n. 3, p. 401-409, jul.-set., 2013

ISSN 0103-9954

\title{
SUBSTRATOS DE ORIGEM ORGÂNICA PARA PRODUÇÃO DE MUDAS DE TECA (Tectona grandis Linn. F.)
}

\author{
SUBSTRATES OF ORGANIC ORIGIN FOR PRODUCTION OF SEEDLINGS OF TEAK (Tectona \\ grandis Linn. F.)
}

Paulo André Trazzi ${ }^{1}$ Marcos Vinicius Winckler Caldeira ${ }^{2}$ Renato Ribeiro Passos ${ }^{3}$

Elzimar de Oliveira Gonçalves ${ }^{4}$

\begin{abstract}
RESUMO
A utilização de resíduos renováveis como fonte de nutrientes para produção de mudas florestais pode ser uma solução para problemas ambientais, principalmente relacionados à destinação destes materiais. Neste contexto, este trabalho teve por objetivo avaliar a utilização de substratos renováveis como componentes de substrato na produção de mudas de teca. As mudas foram produzidas em tubetes com capacidade volumétrica de $280 \mathrm{~cm}^{3}$, utilizando-se para a composição dos tratamentos esterco bovino, cama de frango ou esterco de codorna associados à terra de subsolo e a uma fração de $25 \%$ de substrato comercial florestal. Noventa dias após a repicagem das plântulas, foram analisadas as seguintes características morfológicas: altura da parte aérea (H), diâmetro do coleto (D), massa seca da parte aérea (MSPA), radicular (MSR) e total (MST) e o índice de qualidade de Dickson (IQD). Os resultados indicaram que as mudas produzidas com substratos formulados com a cama de frango apresentaram os maiores valores das características analisadas, sendo que o tratamento com 35\% deste material proporcionou os maiores índices em $\mathrm{H}, \mathrm{D}, \mathrm{MSPA}$, MSR, MST e IQD. A utilização de substratos renováveis pode ser indicada para produção de mudas de teca, contribuindo para a melhoria das propriedades químicas dos substratos formados e, consequentemente, para a nutrição das plantas.
\end{abstract}

Palavras-chave: esterco bovino; esterco de codorna; cama de frango; mudas florestais.

\begin{abstract}
The utilization of renewable waste as a source of nutrients for forest seedlings production can be a solution to environmental problems, mainly related to the disposal of these materials. In this context, this study aimed to evaluate the use of renewable substrates as substrate components in the production of teak seedlings. Seedlings were grown in tubes with a volume capacity of $280 \mathrm{~cm}^{3}$, using for the composition of treatments cattle manure, poultry litter or manure quail associated with subsoil earth and a fraction of $25 \%$ of commercial forestry substrate, and the formed substrates were subjected to chemical analysis. Ninety days after transplanting the seedlings, the following morphological characteristics were analyzed: shoot height, stem diameter, dry weight of shoots, roots and total and Dickson quality index. The results indicated that the seedlings produced with substrates formulated with poultry litter had the highest growth from the traits studied, given that the treatment with $35 \%$ of this material provided the greatest gains. The use of renewable substrates may be indicated for forest seedling production, contributing for the improvement of
\end{abstract}

1 Engenheiro Florestal, Doutorando pelo programa de Pós-Graduação em Engenharia Florestal, Universidade Federal do Paraná, Rua Pref. Lhotário Meissner, 900, Jardim Botânico, CEP 80210-170, Curitiba (PR). patrazzi@hotmail.com

2 Engenheiro Florestal, Dr., Professor do Departamento de Ciências Florestais e da Madeira, Universidade Federal do Espírito Santo, Alto Universitário, s/n, Guararema, Caixa Postal 16, CEP 29500-000, Alegre (ES). Bolsista de produtividade em pesquisa do CNPq. caldeiramv@pq.cnpq.br

3 Engenheiro Agrônomo, Dr., Professor do Departamento de Produção Vegetal, Universidade Federal do Espírito Santo, Alto Universitário, s/n, Guararema, Caixa Postal 16, CEP29500-000, Alegre (ES). Bolsista de produtividade em pesquisa do CNPq. renatopassos@cca.ufes.br

4 Engenheira Florestal, Dr ${ }^{\mathrm{a}}$., Professora do Departamento de Ciências Florestais e da Madeira, Universidade Federal do Espírito Santo, Alto Universitário, s/n, Guararema, Caixa Postal 16, CEP29500-000, Alegre (ES). elzimargoncalves@ufes.br

Recebido para publicação em 6/06/2011 e aceito em 27/04/2012

Ci. Fl., v. 23, n. 3, jul.-set., 2013 
the chemical properties of substrates formed and consequently for the plant nutrition.

Keywords: cattle manure; quail manure; poultry litter; forest seedlings.

\section{INTRODUÇÃO}

Teca (Tectona grandis Linn. F.) é uma espécie arbórea decídua de floresta tropical, pertencente à família Lamiaceae (SOUZA e LORENZI, 2008). Sua madeira é de excepcional qualidade, de elevado valor e alta procura no mercado internacional, representando uma combinação de beleza, estabilidade, durabilidade, resistência, além de ser facilmente trabalhada (FIGUEIREDO et al., 2005). Pode ser utilizada na construção naval, construção de móveis, estruturas, pisos, chapas, painéis, postes e dormentes, mas especialmente na produção de peças de usos nobres e móveis finos devido à sua resistência à ação do sol, calor, frio, água de chuva e do mar (GOMES, 2002). Estima-se que os reflorestamentos com teca, no mundo, já somam mais de três milhões de hectares, e no Brasil, a superfície plantada vem crescendo nos últimos anos, tendo atualmente cerca de 65 mil hectares (ABRAF, 2010), sendo na sua maioria localizados no estado de Mato Grosso, o qual possui condições adequadas para o desenvolvimento da espécie, o que proporciona taxas de crescimento superiores às dos plantios da maioria dos países produtores dessa madeira (PASSOS et al., 2006).

Um dos fatores prioritários para a implantação de povoamentos florestais é a qualidade da muda, que está diretamente ligada à produtividade $\mathrm{e}$ à qualidade do produto final. Por isso, muitos esforços têm sido realizados para melhorar a qualidade e reduzir os custos de produção das mudas. A utilização de materiais renováveis como fonte de nutrientes, além de ser uma interessante solução para destinação dos resíduos, pode também ser uma saída efetiva para a redução dos altos custos de insumos necessários para produção de mudas florestais.

Os compostos orgânicos podem ser utilizados como importante fonte de matéria orgânica e nutrientes para a formulação de um substrato adequando, pois estimulam o desenvolvimento de microrganismos benéficos, proporcionam aumento da capacidade de retenção de água e de nutrientes, melhoram o arejamento e a agregação do substrato às raízes das plantas e aumentam a disponibilidade de nutrientes para a muda. Os compostos atuam, também, no aumento do $\mathrm{pH}$ e nos teores de cátions trocáveis (WENDLING e GATTO, 2002).
O esterco estabilizado biologicamente pode ser uma alternativa viável para misturas com outros substratos. A adubação orgânica com esterco bovino é uma prática milenar, tendo perdido prestígio com a introdução da adubação mineral (BLAISE et al., 2005).

O esterco de aves é aplicado normalmente junto com a cama, que é colocada para acomodar frangos em aviários. Este material quando bem curtido, apresenta-se bem farelado, escuro e frio, muito rico em nitrogênio e sem excesso de amônia (WEINÄRTNER et al., 2006), tornando-se um material bastante interessante na composição de um substrato.

Com base na importância da utilização de materiais renováveis para a produção de mudas, o presente trabalho teve por objetivo avaliar a utilização de estercos de animais como componente de substrato na produção de mudas de teca, avaliando as características de qualidade das mudas em relação aos atributos químicos e físicos dos substratos formados com estes resíduos.

\section{MATERIAL E MÉTODOS}

O experimento foi desenvolvido no Viveiro Florestal do Departamento de Ciências Florestais e da Madeira do Centro de Ciências Agrárias da Universidade Federal do Espírito Santo (CCAUFES), no município de Alegre, o qual possui altitude média de $277 \mathrm{~m}$ e coordenadas geográficas de $20^{\circ} 45^{\prime} \mathrm{S}$ e $41^{\circ} 31^{\prime} \mathrm{W}$. O clima se caracteriza por um inverno seco e verão chuvoso (Cwa - classificação de Köppen), com precipitação anual média de $1104 \mathrm{~mm}$ e temperatura média anual de $24,1^{\circ} \mathrm{C}$, com máximas diárias de $31^{\circ} \mathrm{C}$ e mínimas de $20,2^{\circ} \mathrm{C}$ (MAIA et al., 2007).

Para composição dos tratamentos foi utilizado esterco bovino, cama de frango e esterco de codorna, associados às diferentes proporções de terra de subsolo (Tabela 1). Para dar mais consistência e porosidade ao substrato, foi utilizada uma fração de $25 \%$ de substrato comercial florestal para todas as combinações entre estercos de animais e terra de subsolo.

Utilizou-se o delineamento inteiramente casualizado, considerando dez tratamentos com seis repetições por tratamento, sendo cada repetição 
TABELA 1: Substratos formulados (v:v:v) com esterco bovino, cama de frango e esterco de codorna associados à terra de subsolo e ao substrato comercial florestal.

TABLE 1: Substrates formulated (v:v:v) with cattle manure, poultry litter and manure quail associated with subsoil earth and commercial forestry substrate.

\begin{tabular}{cccccc}
\hline Tratamentos & $\begin{array}{c}\text { Substrato comercial } \\
\text { Florestal }\end{array}$ & $\begin{array}{c}\text { Terra de } \\
\text { subsolo }\end{array}$ & Esterco bovino & $\begin{array}{c}\text { Cama de } \\
\text { frango }\end{array}$ & $\begin{array}{c}\text { Esterco de } \\
\text { codorna }\end{array}$ \\
\hline B1 & $25 \%$ & $40 \%$ & $35 \%$ & - & - \\
B2 & $25 \%$ & $50 \%$ & $25 \%$ & - & - \\
B3 & $25 \%$ & $60 \%$ & $15 \%$ & - & - \\
F1 & $25 \%$ & $40 \%$ & - & $35 \%$ & - \\
F2 & $25 \%$ & $50 \%$ & - & $25 \%$ & - \\
F3 & $25 \%$ & $60 \%$ & - & $15 \%$ & - \\
C1 & $25 \%$ & $40 \%$ & - & - & $35 \%$ \\
C2 & $25 \%$ & $50 \%$ & - & - & $25 \%$ \\
C3 & $25 \%$ & $60 \%$ & - & - & $15 \%$ \\
\hline SCF & & $100 \%$ Substrato comercial florestal & \\
\hline
\end{tabular}

constituída por quatro plantas. Para comparação das médias, foi utilizado o teste de Scott-Knott, ao nível de $5 \%$ de probabilidade.

$\mathrm{O}$ esterco bovino e o esterco de codorna foram coletados na Área Experimental do CCA/ UFES. A cama de frango foi doada pelo Instituto Federal de Educação, Ciência e Tecnologia do Espírito Santo, campus de Alegre-ES. O esterco bovino, a cama de frango e o esterco de codorna passaram por processo de estabilização biológica no próprio viveiro, durante cerca de 30,60 e 90 dias, respectivamente, onde permaneceram depositados em local aberto. Depois de curtidos passaram por peneiras de $3 \mathrm{~mm}$ de malha.

A terra de subsolo utilizada como componente de substrato foi um Latossolo VermelhoAmarelo (EMBRAPA, 2006) coletado na profundidade de 20-40 cm, na Área Experimental do CCA/ UFES. Para compor o substrato, a terra de subsolo foi peneirada em malha de $3 \mathrm{~mm}$.

O experimento foi instalado no dia 15 de dezembro de 2009, sendo as mudas produzidas a partir de sementes, cujos frutos foram obtidos através de doação da empresa Floresteca S.A. Para quebra de dormência, estes frutos foram colocados imersos em água por três noites e postos em pleno sol durantes três dias, segundo recomendações de Figueiredo et al. (2005). Em seguida, os frutos foram colocados em canteiro de areia lavada para germinação.

Após atingirem altura entre cinco e sete centímetros, as plântulas foram repicadas para os tubetes, preenchidos com substratos de seus respectivos tratamentos. Os tubetes cônicos de polipropi- leno, cuja capacidade volumétrica era de $280 \mathrm{~cm}^{3}$, foram acondicionados, na casa de sombra (com sombrite de $50 \%$ ), em bandejas com capacidade de 54 tubetes, sendo estas dispostas em bancadas suspensas a $80 \mathrm{~cm}$ do solo.

As mudas permaneceram na casa de sombra durante 90 dias, sendo irrigadas quatro vezes ao dia, por sistema de irrigação automático. Em dias chuvosos, a irrigação foi cessada.

Visando avaliar somente a influência dos substratos na nutrição das mudas, não houve qualquer adubação de base e de cobertura.

$\mathrm{O}$ experimento foi avaliado noventa dias após a repicagem (15 de março de 2010), analisando as seguintes características morfológicas: altura da parte aérea $(\mathrm{H})$, diâmetro do coleto $(\mathrm{D})$, massa seca da parte aérea (MSPA) e massa seca radicular (MSR). A H foi determinada a partir do nível do substrato até a inserção da última folha, com auxílio de uma régua graduada em milímetros; o D medido na altura do colo da planta, com auxílio de um paquímetro digital; as raízes foram separadas da parte aérea, lavadas, acondicionadas em sacos de papel e secas em estufa com circulação forçada de ar a $70^{\circ} \mathrm{C}$ até alcançar massa constante, obtendo-se a MSR. A MSPA foi determinada através do corte da planta ao nível do substrato obtido a partir do material seco em estufa com circulação forçada de ar, a $70^{\circ} \mathrm{C}$ até atingir peso constante.

A massa seca total e o Índice de qualidade de Dickson (IQD) (DICKSON et al., 1960; citado por FONSECA et al., 2002) foram calculados com em função das características morfológicas citadas, 
sendo a MST determinada pela soma da MSPA e MSR, e o IQD calculado através da fórmula:

$$
\mathrm{IQD}=\frac{\text { MST }}{\mathrm{H} / \mathrm{D}+\mathrm{MSPA} / \mathrm{MSR}}
$$

A análise química dos tratamentos e dos componentes dos tratamentos foi determinada no Laboratório de Recursos Hídricos do Departamento de Ciências Florestais e da Madeira do CCA-UFES, Jerônimo Monteiro, ES, conforme metodologia da EMBRAPA (1999) - Tabela 2.

\section{RESULTADOS E DISCUSSÃO}

O uso de esterco bovino, cama de frango e esterco de codorna como componente de substrato proporcionou efeito significativo $(\mathrm{p}<0,05)$ para as variáveis: altura da parte aérea, diâmetro do coleto, massa seca da parte aérea, massa seca radicular, massa seca total e índice de qualidade de Dickson.

As mudas apresentaram crescimento médio em altura entre 8,86 e $22,31 \mathrm{~cm}$ planta $^{-1}$. A maior média ocorreu no tratamento $\mathrm{F} 1$, diferenciando-se dos demais. O tratamento $\mathrm{F} 2$ apresentou crescimento médio em altura de $16,46 \mathrm{~cm}$, sendo superado apenas pelo tratamento F1. Os tratamentos B3,
C2 e C3 apresentaram o menor crescimento em altura, diferenciando-se dos demais (Figura 1).

$\mathrm{O}$ crescimento em diâmetro das mudas de teca variou de 3,66 a 5,79 $\mathrm{cm}_{\text {planta }}{ }^{-1}$. A maior média foi obtida no tratamento F1, diferenciando-se estatisticamente entre as demais médias. Os tratamentos B3, F3, C2, C3 e SCF apresentaram as mais baixas médias de crescimento em diâmetro do coleto, diferenciando-se estatisticamente dos demais (Figura 1).

Por meio dos resultados apresentados, pode-se inferir que os tratamentos formados a partir da cama de frango foram os que apresentaram maior crescimento em altura e diâmetro. Na Tabela 2, é possível observar que este resíduo apresenta altos teores de nutrientes, principalmente $\mathrm{N}$ e $\mathrm{P}$, e de acordo com Graciano et al. (2006), estes nutrientes são os que mais comumente limitam o crescimento de mudas na fase inicial de produção.

Também podem ser constatado que os tratamentos constituídos com o esterco de codorna foram os que apresentaram as menores médias de altura da parte aérea e do diâmetro do coleto. Esse material é tão rico em nutrientes quanto a cama de frango (Tabela 2), no entanto, não resultou no mesmo desempenho para as mudas de teca.

Uma provável explicação é pelo fato do esterco de codorna apresentar altos teores de $\mathrm{Na}$, o que

TABELA 2: Teores totais de macro e micronutrientes, matéria orgânica (MO) e relação $\mathrm{C} / \mathrm{N}$ dos substratos formulados com esterco bovino (EB), cama de frango (CF) ou esterco de codorna (EC) associado à terra de subsolo (TS) e ao substrato comercial florestal (SCF).

TABLE 2: Total concentrations of macro and micronutrients, organic matter (MO) and $\mathrm{C} / \mathrm{N}$ ratio of substrates formulated with cattle manure (EB), poultry litter (CF) or quail manure (EC) associated with subsoil (TS) and commercial forestry substrate (SCF).

\begin{tabular}{|c|c|c|c|c|c|c|c|c|c|c|c|c|c|}
\hline \multirow{2}{*}{ Tratamentos } & $\mathrm{N}$ & $\mathrm{P}$ & $\mathrm{K}$ & $\mathrm{Ca}$ & $\mathrm{Mg}$ & $\mathrm{S}$ & $\mathrm{Zn}$ & $\mathrm{Fe}$ & $\mathrm{Mn}$ & $\mathrm{Cu}$ & $\mathrm{B}$ & $\mathrm{MO}$ & $\mathrm{C} / \mathrm{N}$ \\
\hline & \multicolumn{11}{|c|}{--------------------- g kg-1 --------------------- } & \multicolumn{2}{|l|}{$\mathrm{g} \mathrm{kg}^{-1}$} \\
\hline B1 & 2,1 & 1,1 & 2,2 & 6,1 & 2,6 & 0,07 & 52 & 32640 & 154 & 10 & 4 & 33,1 & 9,1 \\
\hline B2 & 1,8 & 0,9 & 1,7 & 7,2 & 3,5 & 0,06 & 47 & 31520 & 118 & 7 & 4 & 30,4 & 9,8 \\
\hline B3 & 1,8 & 0,9 & 1,4 & 9,3 & 3,4 & 0,06 & 40 & 32400 & 109 & 8 & 4 & 26,5 & 8,5 \\
\hline F1 & 3,9 & 3,0 & 1,4 & 6,7 & 2,5 & 0,06 & 110 & 29160 & 138 & 22 & 7 & 34,1 & 5,1 \\
\hline F2 & 2,5 & 1,6 & 1,4 & 13,0 & 2,2 & 0,06 & 69 & 34680 & 125 & 14 & 2 & 27,1 & 6,3 \\
\hline F3 & 2,5 & 1,6 & 1,4 & 4,5 & 1,9 & 0,06 & 66 & 35280 & 109 & 16 & 5 & 24,3 & 5,6 \\
\hline $\mathrm{C} 1$ & 3,2 & 3,0 & 1,8 & 19,1 & 2,3 & 0,07 & 94 & 33240 & 121 & 17 & 9 & 36,8 & 6,7 \\
\hline $\mathrm{C} 2$ & 2,1 & 2,1 & 1,7 & 14,2 & 2,2 & 0,07 & 79 & 36160 & 128 & 14 & 6 & 32,5 & 9,0 \\
\hline $\mathrm{C} 3$ & 2,5 & 1,3 & 1,3 & 4,9 & 1,3 & 0,07 & 61 & 37560 & 91 & 14 & 7 & 25,0 & 5,8 \\
\hline $\mathrm{SCF}$ & 8,8 & 1,6 & 1,2 & 8,3 & 4,1 & 0,06 & 44 & 9200 & 199 & 10 & 14 & 145,9 & 9,6 \\
\hline $\mathrm{TS}$ & 0,4 & 0,5 & 0,8 & 11,4 & 2,2 & 0,06 & 39 & 37880 & 83 & 11 & 9 & 7,0 & 10,2 \\
\hline EB & 4,6 & 1,6 & 4,5 & 12,7 & 5,1 & 0,05 & 68 & 12560 & 216 & 11 & 10 & 84,0 & 10,6 \\
\hline $\mathrm{CF}$ & 7,7 & 4,6 & 2,4 & 14,2 & 5,7 & 0,06 & 256 & 7600 & 259 & 40 & 18 & 81,0 & 6,1 \\
\hline $\mathrm{EC}$ & 7,7 & 4,8 & 4,3 & 35,7 & 4,8 & 0,09 & 219 & 9720 & 197 & 25 & 17 & 107,7 & 8,1 \\
\hline
\end{tabular}



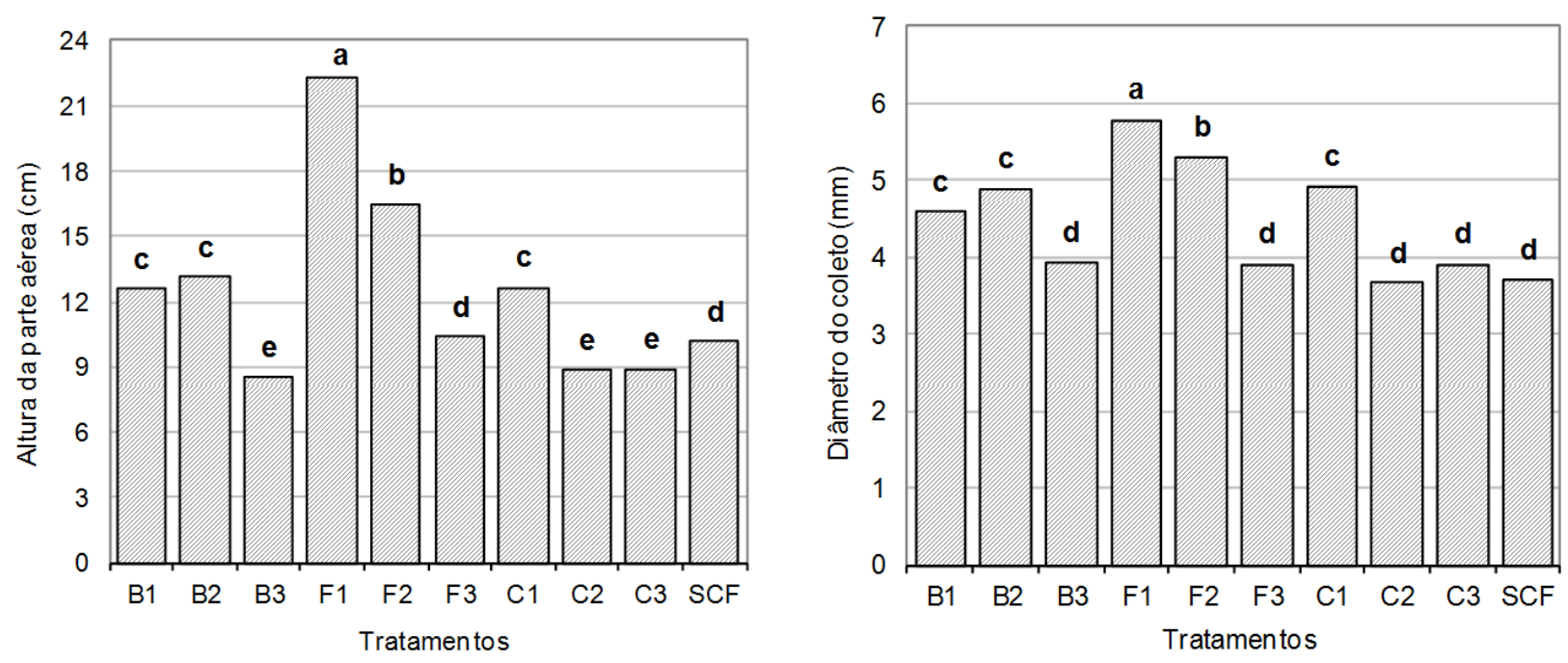

FIGURA 1: Altura da parte aérea e diâmetro do coleto nas mudas de teca produzidas em diferentes substratos. Letras diferentes acima das colunas indicam diferenças significativas pelo Teste de Tukey $(\mathrm{p}<0,05)$.

FIGURE 1: Shoot height and stem diameter in seedlings of teak grown on different substrates. Different letters above the columns indicate significant differences by Tukey test $(\mathrm{p}<0,05)$.

pode ter causado salinização nos substratos (Tabela 2). De acordo com Viana et al. (2001), a salinização leva ao desbalanço nutricional, uma vez que o excesso de sais $(\mathrm{Na}$ e $\mathrm{Cl})$ na solução do solo leva a um distúrbio na absorção de nutrientes, alterando as concentrações de nutrientes, como $\mathrm{Ca}, \mathrm{K}, \mathrm{Mg}$ e $\mathrm{Na}$ na planta. Essa desordem nutricional pode levar a um desenvolvimento abaixo do normal, o que é afetado, em grande parte, pelos processos metabólicos da planta. $\mathrm{O} \mathrm{Na}$ é um metal alcalino, que juntamente com o $\mathrm{Ca}, \mathrm{Mg}$ e $\mathrm{K}$, constituem os cátions trocáveis do meio. Quanto mais alta a porcentagem de $\mathrm{Na}$ entre os cátions trocáveis, menor será a saturação dos sítios de troca do solo ocupados pelo $\mathrm{Ca}, \mathrm{Mg}$ e $\mathrm{K}$.

Ao trabalhar com crescimento e nutrição mineral de mudas de Azadirachta indica e Melia azedarach submetidas à salinidade, Freire et al. (2010) constataram que a salinidade promoveu a perda de crescimento em altura da planta em ambas as espécies.

Em trabalho com leucena (Leucaena leucocephala) e flamboyant (Delonix regia), Lucena et al. (2006), ao avaliarem a influência de diferentes substratos orgânicos (esterco bovino, de galinha e de minhoca) nas proporções de 1:1 e 1:2 com terra de subsolo, concluíram que leucena obteve maior crescimento em altura da parte aérea e diâmetro do coleto nos tratamentos constituídos com os três resíduos orgânicos na proporção 1:1 com a terra de sub- solo. Já para flamboyant, os autores concluíram que os tratamentos com esterco de galinha (proporções de 1:1 e 1:2 com terra de subsolo) proporcionaram maiores crescimentos em altura da parte aérea e diâmetro do coleto para as mudas desta espécie.

Testando a cama de frango associada à terra de subsolo como substrato para a produção de mudas de tamarindeiro, Pereira et al. (2010) concluíram que a melhor proporção para o crescimento dessas mudas foi $60 \%$ de terra de subsolo $+40 \%$ de cama de frango, resultando em plantas de vigoroso crescimento em altura e diâmetro.

Em estudo com Schinus terebinthifolius, Archontophoenix alexandrae e Archontophoenix cunninghamiana, Caldeira et al. (2007) observaram que o substrato padrão (50\% de esterco bovino, $25 \%$ de casca de arroz e $25 \%$ de argila) apresentou resultados semelhantes para o crescimento em altura comparado aos tratamentos à base de resíduos da indústria de algodão, para as três espécies.

Assim como para as variáveis altura e diâmetro, os tratamentos formados com cama de frango resultaram em maiores ganhos em biomassa aérea e radicular. Foi observada uma média em massa seca da parte aérea entre 0,99 a 3,86 $\mathrm{g} \mathrm{planta}^{-1}$. As mudas produzidas no tratamento $\mathrm{F} 1$ alcançaram a maior média de massa seca da parte aérea, diferenciando estatisticamente das demais. $\mathrm{O}$ tratamento $\mathrm{F} 2$ foi estatisticamente inferior apenas em relação ao trata- 
mento F1. Já os tratamentos B3, F3, C1, C3 e SCF apresentaram as mais baixas médias de massa seca da parte aérea, diferenciando-se estatisticamente dos outros tratamentos.

Em experimento com Cassia siamea e Enterolobium maximum, Lucena et al. (2007) ao formularem compostos com terra de subsolo e esterco bovino ou esterco de galinha ou esterco de minhoca, nas proporções 1:1 e 2:1 (v:v), constataram que não houve diferença significativa entre a massa seca da parte aérea nos tratamentos com esterco de galinha e esterco bovino para ambas as espécies.

Para a massa seca radicular, os valores encontrados ficaram entre 0,69 a 2,07 g planta $^{-1}$, sendo a maior média obtida no tratamento F1. Os tratamen-

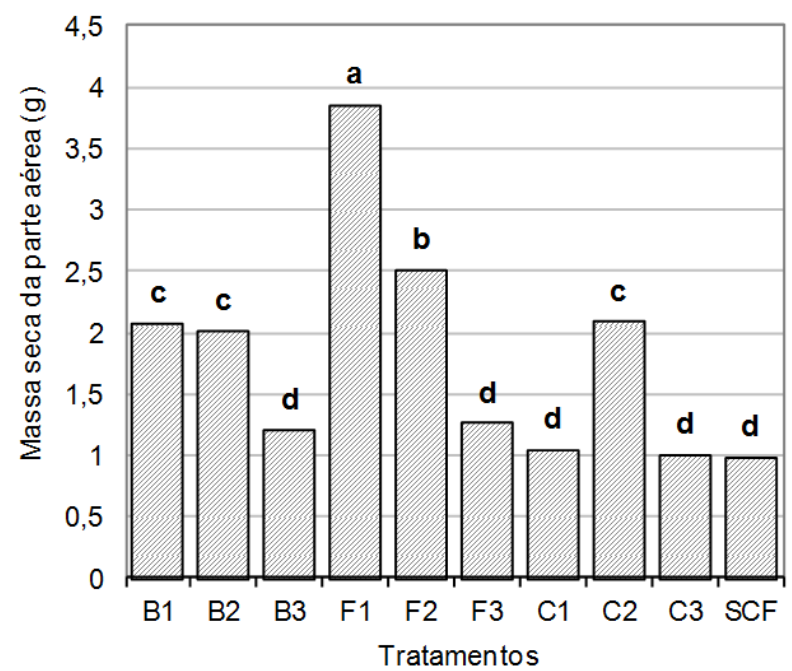

tos $\mathrm{C} 1, \mathrm{C} 3$ e SCF apresentaram média mais baixa de massa seca radicular entre os tratamentos, sendo estatisticamente inferiores em relação aos demais (Figura 2).

Trabalhando com doses de esterco bovino, Prestes (2007) constatou que doses crescentes até $50 \%$ de esterco bovino promoveram crescimento radicular, e a partir desta dosagem, houve um decréscimo na produção em massa radicular para as mudas de angico (Anadenanthera macrocarpa). Oliveira et al. (2004), ao avaliarem o crescimento de quatro espécies florestais, produzidas em diferentes substratos, constataram que não houve diferenças significativas no crescimento radicular das mudas produzidas nos substratos com esterco bovino e esterco de

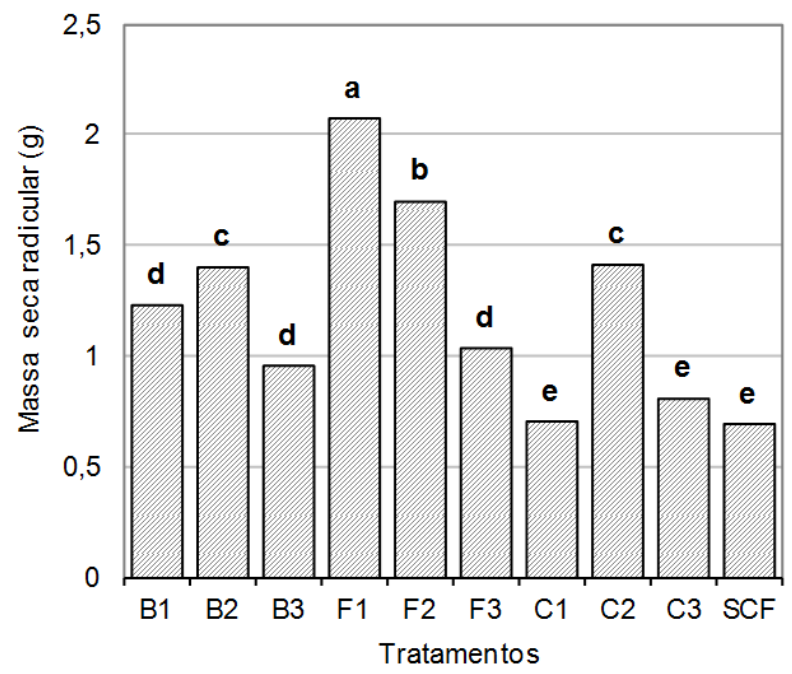

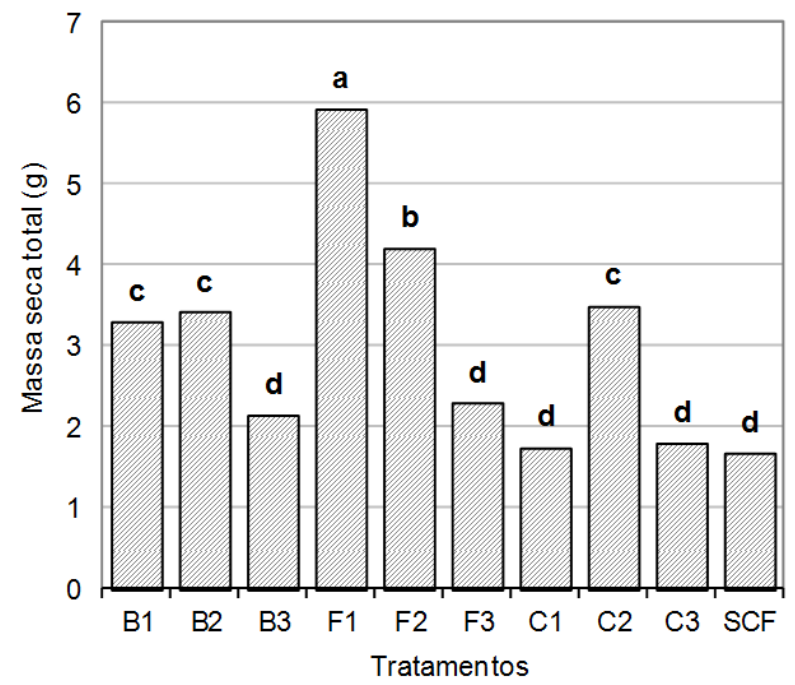

FIGURA 2: Massa seca da parte aérea, massa seca radicular e da massa seca total nas mudas de teca produzidas em diferentes substratos renováveis. Letras diferentes acima das colunas indicam diferenças significativas pelo Teste de Tukey $(\mathrm{p}<0,05)$.

FIGURE 2: Shoot dry mass, root dry mass and total dry mass on seedlings of teak grown on different renewable substrate. Different letters above the columns indicate significant differences by Tukey test $(\mathrm{p}<0,05)$. 
galinha, para aroeirinha (Schinus terebinthifolius), acácia (Acacia holocericeae), eucalipto (Eucalyptus urophyla) e cedro australiano (Toona ciliata).

Para a massa seca total, os resultados não foram diferentes da massa seca da parte aérea e radicular. As mudas alcançaram valores entre 1,68 a 5,93 g planta $^{-1}$, sendo o maior valor obtido no tratamento $\mathrm{C} 1$, seguido do tratamento $\mathrm{C} 2$. $\mathrm{E}$ os tratamentos B3, F3, C1, C3 e SCF promoveram estatisticamente o menor incremento de biomassa total nas mudas de teca.

Avaliando a produção de biomassa de mudas de acácia (Acacia holosericea) submetidas a diferentes soluções nutritivas com exclusão de macronutrientes, Sarcinelli et al. (2004) constataram que as maiores reduções na produção de massa seca total foram verificadas para as plantas submetidas aos tratamentos sem $\mathrm{N}$ ou sem $\mathrm{Mg}$, ou sem $\mathrm{S}$ ou sem K. Sendo assim, é possível considerar que esses elementos são fundamentais para o incremento da massa seca total desta espécie.

Através dos resultados apresentados, é possível observar que o maior ganho de massa seca ocorreu nos tratamentos constituídos por cama de frango, assim como para a altura e para o diâmetro. Uma explicação provável é devido aos altos teores de nutrientes encontrados nos tratamentos formados com este resíduo (Tabela 2).

Foi verificado que os tratamentos formados com esterco de codorna apresentaram as menores médias de incremento em massa seca. Esses substratos apresentam características químicas similares aos substratos formulados com cama de frango (Tabela 2), porém, os resultados apresentados foram diferentes comparando tais tratamentos. Como já explicado anteriormente, os altos teores de Na no esterco de codorna podem ter influenciado negativamente os resultados.

Os valores de IQD das mudas de teca alcançaram valores entre 0,40 a 1,04 (Figura 2). As maiores médias foram encontradas nos tratamentos F1, F2 e C2. Já os tratamentos C1 e SCF apresentaram as menores médias de IQD nas mudas de teca (Figura $3)$.

Oliveira et al. (2004), produzindo mudas de quatro espécies florestais com diferentes substratos constituídos por esterco de frango (40\%) ou esterco bovino $(50 \%)$ na sua composição, encontraram valores de 0,05 e 0,12 para aroeira (Schinus terebinthifolius), 0,02 e 0,05 para acácia (Acacia holocerice$a e$ ), sendo os maiores valores para o tratamento com esterco de frango. Os mesmos autores encontraram

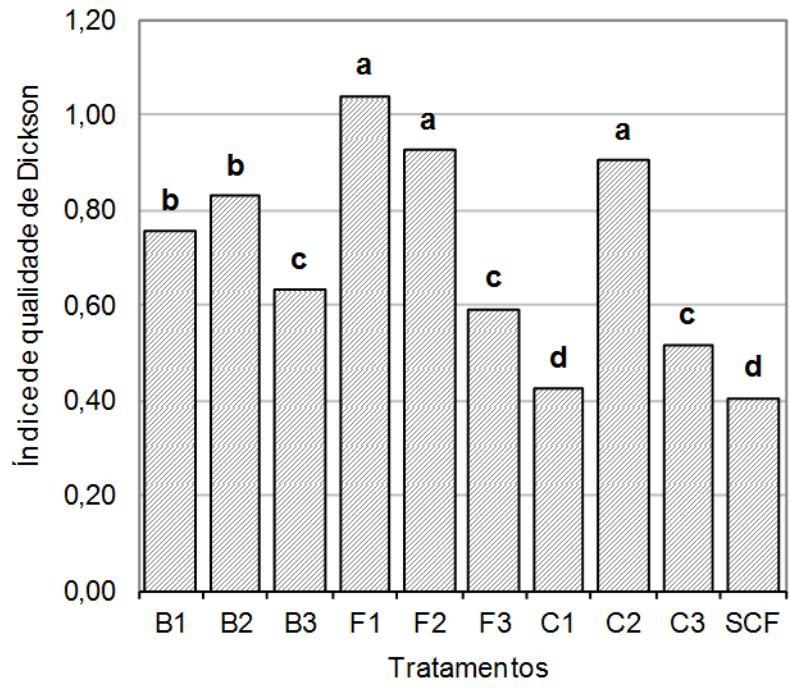

FIGURA 3: Índice de qualidade de Dickson nas mudas de teca produzidas em diferentes substratos. Letras diferentes acima das colunas indicam diferenças significativas pelo Teste de Tukey $(\mathrm{p}<0,05)$.

FIGURE 3: Dickson quality index (DQI) in teak seedlings grown on different substrates. Different letters above the columns indicate significant differences by Tukey test $(\mathrm{p}<0,05)$.

valor de IQD igual a 0,02 para eucalipto (Eucalyptus urophylla), produzido em ambos os substratos, e valores iguais a 0,16 a 0,24 para cedro australiano (Toona ciliata), encontrando a maior média no tratamento com esterco bovino.

Os tratamentos desse estudo proporcionaram ganhos significativos para as mudas de teca. Os substratos utilizados apresentaram elevada disponibilidade de nutrientes para as mudas, mas a principal vantagem dos tratamentos formados por resíduos orgânicos está na sua maior concentração de matéria orgânica comparada a outros materiais, que, segundo Malavolta et al. (2002), alguns adubos orgânicos devem ser empregados em doses elevadas, pois aumentam os teores de matéria orgânica quando incorporados aos substratos. Para Melo (2000), a matéria orgânica, além de constituir um dos principais componente da CTC, durante o processo de mineralização, libera nutrientes para a nutrição das plantas.

\section{CONCLUSÕES}

A utilização de esterco bovino, cama de frango e esterco de codorna como componente dos 
tratamentos proporcionou aumento nos teores totais de nutrientes nos substratos formados.

As mudas produzidas com substratos formulados com cama de frango apresentaram maiores ganhos biométricos, sendo que a proporção de $35 \%$ foi o tratamento que resultou nos maiores índices das características analisadas.

\section{AGRADECIMENTOS}

À CAPES pela concessão de bolsa de doutorado e ao $\mathrm{CNPq}$ pelas bolsas de produtividade científica.

\section{REFERÊNCIAS BIBLIOGRÁFICAS}

ABRAF. Anuário estatístico da ABRAF: ano base 2009. Brasília: ABRAF, 2010. 140 p.

BLAISE, D. et al. Effects of farmyard manure and fertilizers on yield, fibre quality and nutrient balance of rainfed cotton (Gossipium hirsutum). Bioresource Technology, v. 96, p. 345-349, 2005.

CALDEIRA, M. V. W. et al. Influência do resíduo da indústria do algodão na formulação de substrato para produção de Schinus terebinthifolius Raddi, Archontophoenix alexandrae Wendl. et Drude e Archontophoenix cunninghamiana Wendl. et Drude. Revista Ambiência, Guarapuava, v. 3, p. 311-323, 2007.

EMPRESA BRASILEIRA DE PESQUISA AGROPECUÁRIA - EMBRAPA. Manual de análises químicas de solos, plantas e fertilidade. 2. ed. Rio de Janeiro: Embrapa Solos, 1999. 370 p. EMPRESA BRASILEIRA DE PESQUISA AGROPECUÁRIA - EMBRAPA. Sistema brasileiro de classificação de solos. 2 . ed. Rio de Janeiro: Embrapa Solos, 2006. 306 p.

FIGUEIREDO, E. O., OLIVEIRA, L. C., BARBOZA, L. K. Teca (Tectona grandis L.f.): principais perguntas do futuro empreendedor florestal. Rio Branco: Embrapa Acre, 2005.

FONSECA, E. P. et al. Padrão de qualidade de mudas de Trema micrantha (L.) Blume, produzidas sob diferentes períodos de sombreamento. Revista Árvore, Viçosa, v. 26, p. 515-523, 2002.

FREIRE, A. L. O. et al. Crescimento e nutrição mineral do nim (Azadirachta indica a. juss.) e cinamomo (Melia azedarach linn.) submetidos à salinidade. Ciência Florestal, Santa Maria, v. 20, n. 2, p. 207-215, 2010.

GOMES, J. E. Desenvolvimento inicial de Tectona grandis L.f. (Teca) em área de cerrado sob diferentes espaçamentos. 2002. 76 p. Dissertação (Mestrado em Engenharia Florestal) Universidade Federal de Lavras, Lavras, 2002.

GRACIANO, J. D. et al. Efeito da cobertura do solo com cama-de-frango semidecomposta sobre dois clones de mandioquinha-salsa. Acta Scientiarum Agronomy, Maringá, v. 28, n. 3, p. 367-376, 2006. LUCENA, A. M. A; CHAVES, L. H. G.; GUERRA, H. O. C. Desenvolvimento de mudas de cássia e tamboril em diferentes composições de substratos. Revista Verde, Mossoró, v. 2, n. 1, p. 78-84, 2007. LUCENA, A. M. A; GUERRA, H. O. C.; CHAVES, L. H. G. Desenvolvimento de mudas de leucena e flamboyant em diferentes composições de substratos. Revista Verde, Mossoró, v. 1, n. 2, p. 16-23, 2006. MAIA, A. R.; LOPES, J. C.; TEIXEIRA, C. O. Efeito do envelhecimento acelerado na avaliação da qualidade fisiológica de sementes de trigo. Revista Ciência e Agrotecnologia, Lavras, v. 31, n. 3, p. 678-684, 2007.

MALAVOLTA, E.; GOMES, P. F.; ALCARDE, J. C. Adubos e adubações. São Paulo: Nobel, 2002. $200 \mathrm{p}$.

MELO, W. J.; MARQUES, M. O. Potencial do lodo de esgoto como fonte de nutrientes para as plantas. In: BETTIOL, W. ; CAMARGO, O. A. (Eds.). Impacto Ambiental do Uso Agrícola do Lodo de Esgoto. Jaguariúna: Embrapa Meio Ambiente, 2000. p.45-67.

OLIVEIRA, R. B. et al. Desenvolvimento de essências florestais em diferentes substratos. In: ENCONTRO LATINO AMERICANO DE INICIAÇÃO CIENTÍFICA, 7., 2004, São José dos Campos. Anais... São José dos Campos: Instituto de Pesquisas e Desenvolvimento, 2004.

PASSOS, C. A. M.; BUFULIN JUNIOR, L.; GONÇALVES, M. R. Avaliação silvicultural de Tectona grandis L.f., em Cáceres - MT, Brasil: resultados preliminares. Ciência Florestal, Santa Maria, v. 16, n. 2, p. 225-232, 2006.

PEREIRA, P. C. et al. Mudas de tamarindeiro produzidas em diferentes níveis de matéria orgânica adicionada ao substrato. Revista Verde, Mossoró, v. 5, n. 3, p. 152-159, 2010.

PRESTES, M. T. Efeitos de diferentes doses de esterco de gado, no desenvolvimento e no balanço nutricional de mudas do angico (Anadenanthera macrocarpa). 2007. 62 f. Dissertação (Mestrado em Ciências Agrárias) - Universidade de Brasília, Brasília, 2007.

SARCINELLI, T. S. et al. Sintomas de deficiência 
nutricional em mudas de Acacia holosericea em resposta à omissão de macronutrientes. Revista Árvore, Viçosa, v. 28, p. 173-181, 2004.

SOUZA, V. C.; LORENZI, H. Botânica Sistemática: Guia ilustrado para identificação das famílias de Fanerógamas nativas e exóticas no Brasil, baseado em APG II. 2. ed. Nova Odessa: Instituto Plantarum, 2008.

VIANA, A. P. et al. Teores de $\mathrm{Na}, \mathrm{K}, \mathrm{Mg}$ e $\mathrm{Ca}$ em porta-enxertos de videira em solução salina. Revista Scientia agricola, Piracicaba, v. 58, n. 1, p. 187-191, 2001.

WENDLING, I.; GATTO, A. Substratos, adubação e irrigação na produção de mudas. Viçosa: Aprenda Fácil. 2002.

WEINÄRTNER, M. A.; ALDRIGHI, C. F. S.; MEDEIROS, C. A. B. Adubação Orgânica. Pelotas, 2006. 